Hassan, Z., Komaki, A., \& Jafar, J. (2017). Virus-induced manipulation paradigms and alterations in host plants and their vectors. World Journal of Biology and Biotechnology, 2(1), 143-149.

DOI: https://doi.org/10.33865/wjb.002.01.0083

(Online)

ISSN2522-6754

Volume: 02

WORLD JOURNAL \section{2}

2017 OF BIOLOGY
www.sciplatform.com
(Print) ISSN 2518-6746

\title{
VIRUS-INDUCED MANIPULATION PARADIGMS AND ALTERATIONS IN HOST PLANTS AND THEIR VECTORS
}

a Zohaib Ul Hassan* , a Amanmohammad Komaki and b Jahanzeb Jafar

a Department of Plant Protection, Faculty of Agriculture, Ataturk University, Erzurum, Turkey,

b Department of Plant Breeding and Genetics, University of Sargodha. *Corresponding email address: zuhaib1144@gmail.com

\begin{abstract}
This review focuses on virus-plant pathosystems, manipulation paradigms and alterations induced by viruses in their hosts and vectors. After forming a suitable cell environment viruses elude the defense mechanism of cell, having a transformative interaction with hosts and vectors urge the scientists to work on different molecular alterations and manipulations induced by viruses in their hosts and vectors. Different manipulation paradigms are regulated by viruses, that start after acquisition of viruses by corresponding vectors in adaptive manipulation and behavioral manipulation manners, which are generally known as "Host Manipulation Hypothesis" (HMH). Because of these mediated alterations, secondary chemistry of vector's behavior can be affected. In the same way, plants are also extensively influenced by viruses which cause dramatic fluctuations in; genotype, phenotype, metabolism, systemic and hormones of the plants. The combination of viral proteins and host proteins evidenced efficacious viral infection. After viral infection defense system of plants is activated in the way of Induced Systemic Resistance (ISR) that is (1) Rapid/ Extreme resistance (2) Slower host response or (hypersensitive response, HR) also known as programmed death of plant cells. Proteome-level alterations have been reported in phloem sap at the time of virus infection but this phenomenon needs to be investigated. Viruses have also been reported for making alterations in primary phytohormones of plants; Salicylic acid (SA), Abscisic acid (ABA), Jasmonic acid (JA), Ethylene (ET) actively involved in defense mechanism of the plant.
\end{abstract}

Key word: Virus-induced manipulation paradigms, Host manipulation hypothesis, proteome-level alterations, primary phytohormones.

\section{INTRODUCTION}

Innovative, logical, conceptual and scientific paradigms create a new movement, urge and enthusiasm among researchers and scientists. These astonishing paradigms and conceptual settings act as a barrage of studies seeking to authenticate or repudiate the recently anticipated idea. Everything in nature is continually repressed by a diversity of disease causing microorganisms (Jones and Dangl, 2006). In these microorganisms, viruses are one of the tiniest (submicroscopic), particles consisted of a protein coat and nucleic acid core. The genetic data specified to two or more proteins is existed in their nucleic acid. Viruses use the host's biochemical machinery to complete the mechanisms such as the production of proteins (translation) or for the production of the nucleic acid within the host cell (Lodish et al., 2000). Viruses cannot get or stock energy and they are functionally inactive outside their host. Hence, they are usually called as parasites instead of genuine microorganisms. About organisms of all kind have been reported as affected by different viruses, these include animals, plants, fungi, insects and bacteria, but most viruses have specific hosts for infection (Inoue and Tsai, 2013). Viruses are one of the major reasons behind many major plant diseases and are accountable for immense losses in crop yield, production and quality worldwide (Gergerich and Dolja, 2006). The major role in the transmission of plant viruses is played by the insects as they are primarily spread by insect vectors from one field to another. The transmission has been reported an increment with initiation of changes in host or vector behavior. Nevertheless, pathogens and parasites have an influence in changing the behavior of primary hosts and their vectors. The infection produced by plant viruses can induce alterations in their host plants and their aphid vectors (Bosque-Pérez and Eigenbrode, 2011). Virus can induce many alterations and manipulations including; behavioral, adaptive, hormonal, acquisition and others in their host plants as well as in vectors. In last two decades, a respectable number of studies and experiments have been done focusing on the several determinant factors, molecular biology and pathogenesis of plant-pathogenic viruses, which has unlocked the gate to an innovative era in molecular plant virology. Unfortunately, the study about phenomenon of plant patho-systems is very few for evidences of host or vector manipulation by viruses.

Alterations in Vectors after Acquisition of Viruses: Disease causing agents have the trans-mutative interaction with their hosts and vectors impacting upon vector's performance and response which support their advancement (Hurd, 2003; Lei et al., 2016). Different mechanisms are involved in increasing the rate of association between vector and host, by depleting vector generative production, surely altering vector resource management to enlarge accessible nutrient reserves and enhance vector longevity. The acquisition of a plant virus by its insect vector, has the straight effect that alters host selection behavior (Ingwell et al., 2012). For example, aphid 
Rhopalosiphum padi, when acquires Barley yellow dwarf virus (BYDV) in lab. conditions, they were reported as desired to feed on wheat plants having no infection, while non-infective aphids also had a desire to feed appropriately on BYDVinfected plants in vitro. These mechanisms guided us to the development of the "Host Manipulation Hypothesis" (HMH), adaptive manipulation (Poulin, 2000) and behavioral manipulation (Thomas et al., 2005). This hypothesis still has the unexplainable things to be studied.

Behavioral paradigm manipulation: Like a sci-fi novel, the mystery that the behavior of hosts can be influenced, manipulate or controlled by parasites comes into one's mind. But the puzzle of questions likes how and why these diseasecausing agents change behavior in hosts and vectors? are still unanswerable and need to be investigated. As a prevailing hypothesis it is said that most probably, the enhancement in transmission of parasite to another host is influenced by parasites, as they do this by manipulating the behavior of their hosts (Klein, 2005). Through behavioral manipulation parasites can enhance their rate of transmission. For example, in the infectious stage of mosquito as a malaria parasites vector, it is known that the mosquito mechanism manipulate to bite humans more frequently (Koella, 2005). With the way of that behavioral manipulation, parasites are being able to increase the rate of their transmission. In case of Malaria parasite, it uses to manipulate the immune system of both its hosts including vertebrate and mosquito. Some type of immune response is decreased by this manipulation in the vertebrate, e.g. the maturing of the dendritic cell (Urban et al., 1999). The behavior of host can be influenced by parasites in two different direct or indirect manners. Central nervous system and muscle tissue of the host is affected in direct manner. While, the influence in chemical messaging to the CNS and muscles are influenced indirectly (Klein, 2005). The major part of plant viruses is transmitted by their corresponding insect vectors and the feeding behavior of vectors may influence virus. Southern rice black-streaked dwarf virus (SRBSDV) in the white-backed planthopper (WBPH) and in rice plants have been reported as altered the vector's feeding behavior (Lei et al., 2016). Parasites have also the direct effect on the modification of behavior of hosts and vectors (Klein, 2005; Thomas et al., 2005).

Adaptive paradigm manipulation: In recent years, researchers have twisted their investigations towards the matter that plant viruses, are extensively involved in the alteration of phenotypes of their host with the help of vectors in transmission, results manipulating the frequency and nature of host-vector. However, viruses with the multiple hosts raise queries that are they have the same capability in phylogenetically different plans as said before? Viruses have been reported as coevolved with their hosts and vectors. The coevolution of viruses with their hosts and vectors involved the development of host-vector interactions tied with influences intricate in virus evolution (Lovisolo et al., 2003). Some of the plant viruses have been reported to tempt changes in their host plants, due to that reason aphids which carry these viruses settle favorably on infested hosts (Rajabaskar et al., 2014). In monoculture adaptation to local hosts by cucumber mosaic virus (CMV) revealed that this kind of adaptation might spread effects on host-plant traits mediating interactions with aphid vectors (Mauck et al., 2014). The diverse effects of transmitted in persistent manner and non-persistent transmitted (NPT) viruses exhibited on features of host phenotypes which facilitate vector desirability, and scattering from infected host plants (Mauck et al., 2012). The increment in the transmission of the viruses have been reported by altering the important features of their arthropod vectors and vertebrate hosts (Lefevre and Thomas, 2008). Such as, Potato plant (Solanum tuberosum L.) infected by Potato leaf roll virus (PLRV) attracts and capture the primary vector of PLRV, the green peach aphid, Myzus persicae (Sulzer) more efficiently because of the release of volatiles from diseased plants (Ngumbi et al., 2007; Werner et al., 2009; De Vos and Jander, 2010). In another work, Whiteflies of biotypes $\mathrm{B}$ and $\mathrm{Q}$ both have been reported having rapid probing actions with higher amount of feeding sessions; this did not, however, modify the whole time spent feeding. While, they are much more striking to Tomato yellow leaf curl virus TYLCV-infected plants (Liu et al., 2013).

Virus induced alterations in host plants and their effects: As viruses, use the host's biochemical machinery and make lot of variations and alterations in both their vectors and hosts. Plants are one of the most influenced hosts by viruses. Viruses can cause many phenotypic and genotypic changes in host plants. Dramatic fluctuations have been induced in plant host metabolism by virus infection (Handford and Carr, 2006). Plant volatile emission profiles are altered through virus infection, and this can make plants extra striking to viral vectors, such as aphids (De Vos and Jander, 2010). Qualitative and quantitative metabolic changes in the release of volatile compounds, caused by deceptive chemical signals of Cucumber mosaic virus (CMV) make infected host plants much striking to aphid vectors (Mauck et al., 2010). It has been reported that certain alterations induced by CMV in a plant host alter the optimal spread and transmission of the virus by alighting, settling and probing behavior of its key vector Aphis gossypii (Carmo-Sousa et al., 2014). Turnip mosaic virus (TuMV) infections disturb many Arabidopsis developing and evolving traits including metabolism and cell-wall transport. Centers in the interactome affected upon infection (Sánchez et al., 2015). Hop stunt viroid (HSVd) RNA accumulation in Nicotiana benthamiana promoted the gathering of ribosomalderived small RNAs (rb-sRNAs) and alter the host DNA methylation in a reply to constitutive expression (Castellano et al., 2015). The intracellular membrane structures are changed drastically to enhance the replication of viruses in virus-infected plant cells (Hashimoto et al., 2015). Though, it is still unanswerable whether this replication-associated membrane modification is the reason behind the appearance of symptoms or not. 
Systemic Alterations: Replication of genome, cell-to-cell movement and long-distance spread to a larger area through the vascular tissue are necessary in Systemic infection of plants by viruses.

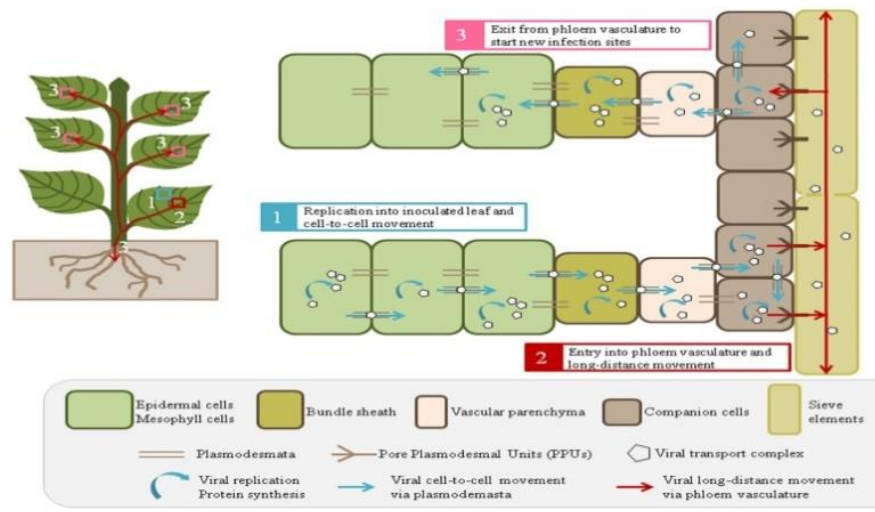

Figure 1: A general view of virus cell-to-cell and long-distance movement in plant tissues (Hipper et al., 2013).

Both viral proteins and host proteins evidenced efficacious viral infection (Mahadevan et al., 2015). The complexity of molecular interactions between host and viral pathogen results in successful systemic infection, which reveals spatial and temporal alterations in plant gene expression (Allie and Rey, 2013). Larger variations in the transcriptome of the leaves of transgenic tobacco plants seen through effect of the Potato virus $x$ PVX-specific P25 VSRS protein, but less amount of any alterations in the new flowers of the same plants (Jada et al., 2013). Virus-induced gene silencing-mediated decontrol the accumulation of reactive oxygen species (ROS) by silencing genome-wide characterization of putative trehalose-related genes and weakened the countenance of defense-related genes upon pathogen infection thus depreciated the resistance against Botrytis cinerea in tomato plant (Zhang et al., 2016). SerraSoriano et al. (2015) investigated the proteome-level alterations happen in phloem sap at the time of virus infection. But there are very few studies present that have truly examined the phloem sap proteome during viral infection.

Induced Systemic Resistance: Induced systemic resistance (ISR) of plants against pathogens and parasites has the potential to use in plant protection and has been intensively studied and experimented regarding the fundamental signaling pathways that are useful in plant protection (Heil and Bostock, 2002). After the ineffectiveness of chemical actions for the management of viruses, the biocontrol agents are making marks in development of innovative management strategies nowadays. In tomato plant treated by Trichoderma harzianum strain T-22 (T22), led plant to a systemic resistance through jasmonic acid/ethylene and salicylic acid signaling pathways against Cucumber mosaic virus (CMV) infection (Vitti et al., 2016). The most important things in defense mechanism are the rapidity of host responses and early reactive oxygen species (ROS) accumulation at virus infection sites. This resistance can be of two types (1) Rapid/ Extreme resistance (2) Slower host response or (hypersensitive response, HR) also known as programmed death of plant cells (Hernández et al., 2016).

Hormonal Alterations in Host Plants after Viral Interaction: Hormones tune the plant's response to stresses caused by biotic agents or abiotic factors. Different complexes are included, through which they tempt responses to diverse stimuli. Symptoms of virus infection may be described as the alterations in amount of a particular plant hormone (Jameson and Clarke, 2002). Hormones included in primary plant defense are; salicylic acid (SA), jasmonic acid (JA), ethylene (Et) and abscisic acid (ABA). But in vulnerable host plants, hormonal distraction caused by viral infections manifests the instantaneous induction of several antagonistic hormones (Alazem and Lin, 2015). However, the association of the cell death with the alterations in gene expression and phytohormone levels caused by corresponding viruses has fewer evidences.

Salicylic Acid (SA): In recent years, scientists and researchers are doing research on extensive signaling role of SA in plants. Salicylic acid (SA) is manufactured by plants in order to encounter diverse series of plant pathogens and is vital to the launch both local and systemic-acquired resistance (SAR) (Loake and Grant, 2007; Vlot et al., 2009). Plum pox virus (PPV) can replicate in inoculated leaves of Nicotiana tabacum. Replication and accumulation of PPV is higher in the locally infected leaves of plants deficient in SA and the accretion of viral derived small RNAs was reduced in the bacterial salicylate hydroxylase (NahG) that degrades salicylic acid (SA), suggesting that SA might act as an enhancer of the RNA-silencing antiviral defense in tobacco (Alamillo et al., 2006). Delay in activation of expression of genes involved in defense responses are due to the absence of SA at the transcriptome level have been reported, which confirmed the major role of SA in arranging Ny-1-mediated hypersensitive resistance (HR) of potato (Solanum tuberosum L.) to Potato virus Y (PVY) (Baebler et al., 2014). In model plant Arabidopsis Isochorismate synthase 1 (ICS1) is required for SA biosynthesis and SA then regulates the ICS1 positively in Plant defense mechanism (Hunter et al., 2013). However, In soybean it has been reported that exogenous treatment of SA did nothing with the levels of Bean pod mottle virus (BPMV) (Singh et al., 2011). Through siRNA pathway SA partially induced the reduction in viral replication and this is the evidence of positive cross-talk SA and siRNA during antiviral defenses (Yu et al., 2003; Campos et al., 2014).

Abscisic Acid (ABA): Abscisic acid is basically sesquiterpene compound, key hormone in modulating the response of plant because it has ability to response and regulate the defense mechanism of plants against many abiotic stresses, which happen during the developmental stage of plant (Atkinson and Urwin, 2012; Lee and Luan, 2012). Furthermore, the role and engrossment of ABA has studied expansively in biotic stresses, but it is less understood and there are fewer evidences about the modulation of ABA during viral induction in plant. The first report about the ABA-virus interaction 
clarified that exogenous abscisic acid was more beneficial in depleting the symptoms of mosaic caused by Tobacco mosaic virus (TMV) but the development and growth of tobacco mosaic virus (TMV) have not been effected by ABA in tomato or tobacco plants (Fraser and Whenham, 1989). ABA has an important role in accumulation of Bamboo mosaic virus (BaMV) and Cucumber mosaic virus (CMV) in hosts Arabidopsis thaliana and Nicotiana benthamiana respectively (Alazem et al., 2014). As RNA silencing which affects local and systemic movement of plant viruses and is considered to be the main defense mechanism of plants against viruses in $R$-gene-specific resistance, ABA has been reported to modulate plant defenses at the level of the RNA silencing machinery, like in PVX (Ruiz-Ferrer and Voinnet, 2009; Jaubert et al., 2011). But there is lot to done about the well characterization of the role of ABA in virus induction and replication in host cell.

Jasmonic Acid (JA)/ jasmonate: Different mechanisms of defense are initiated by plants after attack of any pathogen. Generally, the jasmonate involved in response to shield host plants against a large number of insect herbivores (Thaler et al., 2004). Defense mechanism regulations, up-and downregulation are reliant on signaling pathways facilitated by jasmonic acids JAs along with other stress hormones (e.g. salicylic acid) (Okada et al., 2014). The study has been done that fortification of Arabidopsis against CMV by strain 90-166 follows a signaling pathway for virus protection dependent on jasmonic acid (JA) (Ryu et al., 2004). Silencing of the jasmonic acid perception gene, COI1 (Coronatine insensitive 1), accelerated cell death during infection with compatible viruses (Pacheco et al., 2012; García-Marcos et al., 2013). In recent studies, it has been indicated that jasmonic acid (JA) is a serious transportable signal that starts the systemic resistance against Tobacco mosaic virus (TMV) (Zhu et al., 2014). In Nicotiana benthamiana plants Silencing of SA or JA biosynthetic and signaling genes make plants more susceptible to TMV (Zhu et al., 2014). Hypersensitive response in Nicotiana benthamiana is induced by $\mathrm{N}$ resistance genes against TMV, and this response is mainly regulated by plant-hormones SA and JA. In the tobacco cultivar processing the $\mathrm{N}$ gene, accretion of virus is reduced by the silencing of CORONATINE-INSENSITIVE 1 (COI1), a JA receptor, as ensured that of allene oxide synthase, a biosynthetic enzyme of JA (Oka et al., 2013). The infection of geminivirus is preferably disturbed when Arabidopsis thaliana plants are treated with jasmonate exogenously, It suggests that the decreased response of the jasmonate seem be critical for infection (Lozano-Durán et al., 2011).

Ethylene (ET): Ethylene (ET) is highly activated hormone during certain developmental stages of plant, such as senescence, in addition to the defense response to necrotrophic pathogens (Van der Ent and Pieterse, 2012). Defense response of an ethylene response-related factor, GbERF1-like, from Gossypium barbadense cv. '7124' involved in resistance mechanism of Verticillium dahlia (Guo et al., 2016). However, Et has not been reported as indispensable for plant battle against viruses, just little evidences present linking aparticipation of Et in the development of symptom (Geri et al., 2004). Symptoms like chlorosis and stunting in P6-transgenic (Protein P6 is the foremost symptom determining factor of cauliflower mosaic virus (CaMV)) and CaMV-infected plants are dependent on interactions between P6 (P6 is transactivator (TAV) /viroplasmin protein (Schoelz et al., 2015), and components involved in ethylene signaling (Geri et al., 2004). In a new experiment, mutants of the Et pathway [such as acs1 (1aminocyclopropane-1-carboxylate synthase), erf106 (ethyleneresponsive transcription factor 106) and ein2 (ethylene insensitive 2) has been testified as resistant to TMVcg. Moreover, the accumulation of TMVcg in treated plants showed an increment with the application of 1-aminocyclopropane-1carboxylic acid (ACC) (Chen et al., 2013). It might be possible that Et backs the development of symptom and systemic movement in the case of TMVcg infection. But it is still unclear that how ET positively adjusts the ER response while there is a viral infection?

Table 1. Primary phytohormones and their roles in Plant defense

\begin{tabular}{|c|c|c|}
\hline Hormone & $\begin{array}{l}\text { Basic } \\
\text { Compound }\end{array}$ & Defense Against \\
\hline Salicylic & Phenolic & Local and Systemic \\
\hline $\operatorname{acid}(\mathrm{SA})$ & Compound & infection \\
\hline $\begin{array}{l}\text { Abscisic } \\
\text { acid (ABA) }\end{array}$ & $\begin{array}{l}\text { Sesquiterpene } \\
\text { compound }\end{array}$ & Adaptive stress \\
\hline $\begin{array}{l}\text { Jasmonic } \\
\text { acid (JA) }\end{array}$ & $\begin{array}{l}\text { oxygenated } \\
\text { fatty acid }\end{array}$ & $\begin{array}{l}\text { Necrotrophic pathogens } \\
\text { and } \\
\text { insect infestation }\end{array}$ \\
\hline $\begin{array}{l}\text { Ethylene } \\
\text { (ET) }\end{array}$ & Hydrocarbon & Necrotrophic pathogens \\
\hline
\end{tabular}

While cross communication mediated by different molecular players between classical defense phytohormone is critical for plant battles with disease causing agents and their vectors in which salicylic acid (SA), jasmonic acid (JA), and ethylene (ET) are playing a major role. Plant resistance is controlled and triggered by different low molecular mass signals against biotrophic and necrotrophic pathogens through a composite signaling network that also involves influence of other hormones (Yang et al., 2015).

\section{CONCLUDING AND REMARKS}

By making alterations in hosts, viruses subsequently enhance transmission efficacy by vectors. After acquisition of viruses by vectors different kind of changes can be happened in vectors in diverse manners as these alterations can be transpired in adaptation or behavior of vectors, like longevity of aphids nourishing on all infected-plant infected with Raspberry leaf mottle virus [RLMV; Closterovirus (Closteroviridae)] rises compared with healthy plants. However, aphid productiveness only increased in the coinfection treatment (Raspberry leaf mottle virus [RLMV; Closterovirus (Closteroviridae)] and Raspberry latent virus [RpLV; Reovirus (Reoviridae)] on raspberry plants (Lightle and Lee, 2014). The studies revealed the faster growth rates, 
increased fertility, larger longevity and/or higher production of alate forms of vectors when they feed on virus-infected host (Kennedy, 1951; Fereres and Moreno, 2009; Ingwell et al., 2012), results in an increment of virus spread and are characteristically credited to secondary effects of virus infection on host quality. Temporal changes in hormone signalling and responses are happened after viral infection. As, primary phytohormones of plants; Salicylic acid (SA), Abscisic acid (ABA), Jasmonic acid (JA), Ethylene (ET) actively involved in defense mechanism of plant can be affected temporally after induction of virus to host plants. Viral infections interrupt many other processes like metabolites, transcriptomic and small RNA profiles. Alterations at proteome-level alterations also been reported in phloem sap at the time of virus infection. But there are fewer studies present that have truly inspected the phloem sap proteome during viral infection. The interaction between host and corresponding viruses has extensive and overlapping affects and to elucidate these affects, it is need to wholly recognize the interplay between host and virus (Alazem and Lin, 2015). Additional information, experimentation and investigation are required to elucidate cellular changes at very initial stages of viral infection. Throughout viral infection cell environment is changed (to persuade resistance or to support virus duplication and spread) requires the experimentation and investigation. Upcoming identification of the roles of hormones in plant-virus interactions and cross-talk between hormone pathways will assist to fix the molecular mechanisms by which plants resist infection. These studies extend the scope of the host manipulation hypothesis and alterations during viral infection by demonstrating distinct mechanisms involve in alterations of host plants and manipulations in vectors.

\section{REFERENCES}

Alamillo, J. M., P. Saénz and J. A. García, 2006. Salicylic acidmediated and rna-silencing defense mechanisms cooperate in the restriction of systemic spread of plum pox virus in tobacco. The plant journal, 48(2): 217-227.

Alazem, M., K.-Y. Lin and N.-S. Lin, 2014. The abscisic acid pathway has multifaceted effects on the accumulation of bamboo mosaic virus. Molecular plant-microbe interactions, 27(2): 177-189.

Alazem, M. and N. S. Lin, 2015. Roles of plant hormones in the regulation of host-virus interactions. Molecular plant pathology, 16(5): 529-540.

Allie, F. and M. Rey, 2013. Transcriptional alterations in model host, nicotiana benthamiana, in response to infection by south african cassava mosaic virus. European journal of plant pathology, 137(4): 765-785.

Atkinson, N. J. and P. E. Urwin, 2012. The interaction of plant biotic and abiotic stresses: From genes to the field. Journal of experimental botany, 63(10): 3523-3543.

Baebler, Š., K. Witek, M. Petek, K. Stare, M. Tušek-Žnidarič, M. Pompe-Novak, J. Renaut, K. Szajko, D. Strzelczyk-Żyta and W. Marczewski, 2014. Salicylic acid is an indispensable component of the ny-1 resistance-gene-mediated response against potato virus $\mathrm{y}$ infection in potato. Journal of experimental botany, 65(4): 1095-1109.

Bosque-Pérez, N. A. and S. D. Eigenbrode, 2011. The influence of virus-induced changes in plants on aphid vectors: Insights from luteovirus pathosystems. Virus research, 159(2): 201-205.

Campos, L., P. Granell, S. Tárraga, P. López-Gresa, V. Conejero, J. M. Bellés, I. Rodrigo and P. Lisón, 2014. Salicylic acid and gentisic acid induce rna silencing-related genes and plant resistance to rna pathogens. Plant physiology and biochemistry, 77: 35-43.

Carmo-Sousa, M., A. Moreno, E. Garzo and A. Fereres, 2014. A non-persistently transmitted-virus induces a pull-push strategy in its aphid vector to optimize transmission and spread. Virus research, 186: 38-46.

Castellano, M., G. Martinez, V. Pallás and G. Gómez, 2015. Alterations in host DNA methylation in response to constitutive expression of hop stunt viroid rna in nicotiana benthamiana plants. Plant pathology, 64(5): 1247-1257.

Chen, L., L. Zhang, D. Li, F. Wang and D. Yu, 2013. Wrky8 transcription factor functions in the tmv-cg defense response by mediating both abscisic acid and ethylene signaling in arabidopsis. Proceedings of the national academy of sciences, 110(21): E1963-E1971.

De Vos, M. and G. Jander, 2010. Volatile communication in plant-aphid interactions. Current opinion in plant biology, 13(4): 366-371.

Fereres, A. and A. Moreno, 2009. Behavioural aspects influencing plant virus transmission by homopteran insects. Virus research, 141(2): 158-168.

Fraser, R. and R. Whenham, 1989. Abscisic acid metabolism in tomato plants infected with tobacco mosaic virus: Relationships with growth, symptoms and the tm-1 gene for tmv resistance. Physiological and molecular plant pathology, 34(3): 215-226.

García-Marcos, A., R. Pacheco, A. Manzano, E. Aguilar and F. Tenllado, 2013. Oxylipin biosynthesis genes positively regulate programmed cell death during compatible infections with the synergistic pair potato virus x-potato virus $y$ and tomato spotted wilt virus. Journal of virology, 87(10): 5769-5783.

Gergerich, R. C. and V. V. Dolja, 2006. Introduction to plant viruses, the invisible foe. The plant Health instructor.

Geri, C., A. J. Love, E. Cecchini, S. J. Barrett, J. Laird, S. N. Covey and J. J. Milner, 2004. Arabidopsis mutants that suppress the phenotype induced by transgene-mediated expression of cauliflower mosaic virus (camv) gene vi are less susceptible to camv-infection and show reduced ethylene sensitivity. Plant molecular biology, 56(1): 111-124.

Guo, W., L. Jin, Y. Miao, X. He, Q. Hu, K. Guo, L. Zhu and X. Zhang, 2016. An ethylene response-related factor, gberf1. Plant molecular biology, 91(3): 305-318.

Handford, M. G. and J. P. Carr, 2006. Plant metabolism associated with resistance and susceptibility. In: Natural 
resistance mechanisms of plants to viruses. Springer: pp: 315-340.

Hashimoto, M., K. Komatsu, R. Iwai, T. Keima, K. Maejima, T. Shiraishi, K. Ishikawa, T. Yoshida, Y. Kitazawa and Y. Okano, 2015. Cell death triggered by a putative amphipathic helix of radish mosaic virus helicase protein is tightly correlated with host membrane modification. Molecular plant-microbe Interactions, 28(6): 675-688.

Heil, M. and R. M. Bostock, 2002. Induced systemic resistance (isr) against pathogens in the context of induced plant defences. Annals of botany, 89(5): 503-512.

Hernández, J. A., G. Gullner, M. J. Clemente-Moreno, A. Künstler, C. Juhász, P. Díaz-Vivancos and L. Király, 2016. Oxidative stress and antioxidative responses in plantvirus interactions. Physiological and molecular plant pathology, 94: 134-148.

Hipper, C., V. Brault, V. Ziegler-Graff and F. Revers, 2013. Viral and cellular factors involved in phloem transport of plant viruses. Frontiers in plant science, 4: 154.

Hunter, L. J., J. H. Westwood, G. Heath, K. Macaulay, A. G. Smith, S. A. MacFarlane, P. Palukaitis and J. P. Carr, 2013. Regulation of rna-dependent rna polymerase 1 and isochorismate synthase gene expression in arabidopsis. PLoS One, 8(6): e66530.

Hurd, H., 2003. Manipulation of medically important insect vectors by their parasites. Annual review of entomology, 48(1): 141-161.

Ingwell, L. L., S. D. Eigenbrode and N. A. Bosque-Pérez, 2012. Plant viruses alter insect behavior to enhance their spread. Scientific reports, 2: 578.

Inoue, T. and B. Tsai, 2013. How viruses use the endoplasmic reticulum for entry, replication, and assembly. Cold Spring Harbor perspectives in biology, 5(1): a013250.

Jada, B., A. J. Soitamo and K. Lehto, 2013. Organ-specific alterations in tobacco transcriptome caused by the pvxderived p25 silencing suppressor transgene. BMC plant biology, 13(1): 8.

Jameson, P. E. and S. F. Clarke, 2002. Hormone-virus interactions in plants. Critical reviews in plant sciences, 21(3): 205-228.

Jaubert, M., S. Bhattacharjee, A. F. Mello, K. L. Perry and P. Moffett, 2011. Argonaute2 mediates rna-silencing antiviral defenses against potato virus $\mathrm{x}$ in arabidopsis. Plant physiology, 156(3): 1556-1564.

Jones, J. D. and J. L. Dangl, 2006. The plant immune system. Nature, 444(7117): 323-329.

Kennedy, J., 1951. Benefits to aphids from feeding on galled and virus-infected leaves.

Klein, S. L., 2005. Parasite manipulation of host behavior: Mechanisms, ecology, and future directions. Behavioural processes, 68(3): 219-221.

Koella, J. C., 2005. Malaria as a manipulator. Behavioural processes, 68(3): 271-273.

Lee, S. C. and S. Luan, 2012. Aba signal transduction at the crossroad of biotic and abiotic stress responses. Plant, Cell
\& environment, 35(1): 53-60.

Lefevre, T. and F. Thomas, 2008. Behind the scene, something else is pulling the strings: Emphasizing parasitic manipulation in vector-borne diseases. Infection, genetics and evolution, 8(4): 504-519.

Lei, W., P. Li, Y. Han, S. Gong, L. Yang and M. Hou, 2016. Epg recordings reveal differential feeding behaviors in sogatella furcifera in response to plant virus infection and transmission success. Scientific reports, 6.

Lightle, D. and J. Lee, 2014. Raspberry viruses affect the behavior and performance of amphorophora agathonica in single and mixed infections. Entomologia experimentalis applicata, 151(1): 57-64.

Liu, B., E. L. Preisser, D. Chu, H. Pan, W. Xie, S. Wang, Q. Wu, X. Zhou and Y. Zhang, 2013. Multiple forms of vector manipulation by a plant-infecting virus: Bemisia tabaci and tomato yellow leaf curl virus. Journal of virology, 87(9): 4929-4937.

Loake, G. and M. Grant, 2007. Salicylic acid in plant defence the players and protagonists. Current opinion in plant biology, 10(5): 466-472.

Lodish, H., A. Berk, S. L. Zipursky, P. Matsudaira, D. Baltimore and J. Darnell, 2000. Viruses: Structure, function, and uses.

Lovisolo, O., R. Hull and 0. Rösler, 2003. Coevolution of viruses with hosts and vectors and possible paleontology. Advances in virus research, 62: 325-379.

Lozano-Durán, R., T. Rosas-Díaz, G. Gusmaroli, A. P. Luna, L. Taconnat, X. W. Deng and E. R. Bejarano, 2011. Geminiviruses subvert ubiquitination by altering csnmediated derubylation of scf e3 ligase complexes and inhibit jasmonate signaling in arabidopsis thaliana. The Plant cell, 23(3): 1014-1032.

Mahadevan, C., A. Jaleel, L. Deb, G. Thomas and M. Sakuntala, 2015. Development of an efficient virus induced gene silencing strategy in the non-model wild ginger-zingiber zerumbet and investigation of associated proteome changes. PloS one, 10(4): e0124518.

Mauck, K., N. A. Bosque-Pérez, S. D. Eigenbrode, C. M. Moraes and M. C. Mescher, 2012. Transmission mechanisms shape pathogen effects on host-vector interactions: Evidence from plant viruses. Functional ecology, 26(5): 1162-1175.

Mauck, K., C. De Moraes and M. Mescher, 2014. Evidence of local adaptation in plant virus effects on host-vector interactions. Integrative and comparative biology, 54(2): 193-209.

Mauck, K. E., C. M. De Moraes and M. C. Mescher, 2010. Deceptive chemical signals induced by a plant virus attract insect vectors to inferior hosts. Proceedings of the National Academy of sciences, 107(8): 3600-3605.

Ngumbi, E., S. D. Eigenbrode, N. A. Bosque-Pérez, H. Ding and A. Rodriguez, 2007. Myzus persicae is arrested more by blends than by individual compounds elevated in headspace of plrv-infected potato. Journal of chemical ecology, 33(9): 1733-1747.

Oka, K., M. Kobayashi, I. Mitsuhara and S. Seo, 2013. Jasmonic 
acid plays a negative role in resistance to tobacco mosaic virus in tobacco. Plant and cell physiology: pct137.

Okada, K., H. Abe and G.-i. Arimura, 2014. Jasmonates induce both defense responses and communication in monocotyledonous and dicotyledonous plants. Plant and cell physiology: pcu158.

Pacheco, R., A. García-Marcos, A. Manzano, M. G. de Lacoba, G. Camañes, P. García-Agustín, J. R. Díaz-Ruíz and F. Tenllado, 2012. Comparative analysis of transcriptomic and hormonal responses to compatible and incompatible plant-virus interactions that lead to cell death. Molecular plant-microbe interactions, 25(5): 709-723.

Poulin, R., 2000. Manipulation of host behaviour by parasites: A weakening paradigm? Proceedings of the Royal Society of London B: Biological sciences, 267(1445): 787-792.

Rajabaskar, D., N. A. Bosque-Pérez and S. D. Eigenbrode, 2014. Preference by a virus vector for infected plants is reversed after virus acquisition. Virus research, 186: 32-37.

Ruiz-Ferrer, V. and 0. Voinnet, 2009. Roles of plant small rnas in biotic stress responses. Annual review of plant biology, 60: 485-510.

Ryu, C. M., J. F. Murphy, K. S. Mysore and J. W. Kloepper, 2004. Plant growth-promoting rhizobacteria systemically protect arabidopsis thaliana against cucumber mosaic virus by a salicylic acid and npr1-independent and jasmonic acid-dependent signaling pathway. The Plant Journal, 39(3): 381-392.

Sánchez, F., P. Manrique, C. Mansilla, P. Lunello, X. Wang, G. Rodrigo, S. López-González, C. Jenner, P. González-Melendi and S. F. Elena, 2015. Viral strain-specific differential alterations in arabidopsis developmental patterns. Molecular Plant-microbe interactions, 28(12): 1304-1315.

Schoelz, J. E., C. A. Angel, R. S. Nelson and S. M. Leisner, 2015. A model for intracellular movement of cauliflower mosaic virus: The concept of the mobile virion factory. Journal of experimental botany: erv520.

Serra-Soriano, M., J. A. Navarro, A. Genoves and V. Pallás, 2015. Comparative proteomic analysis of melon phloem exudates in response to viral infection. Journal of proteomics, 124: 11-24.

Singh, A. K., D.-Q. Fu, M. El-Habbak, D. Navarre, S. Ghabrial and A. Kachroo, 2011. Silencing genes encoding omega-3 fatty acid desaturase alters seed size and accumulation of bean pod mottle virus in soybean. Molecular plant-microbe interactions, 24(4): 506-515.

Thaler, J. S., B. Owen and V. J. Higgins, 2004. The role of the jasmonate response in plant susceptibility to diverse pathogens with a range of lifestyles. Plant physiology, 135(1): 530-538.

Thomas, F., S. Adamo and J. Moore, 2005. Parasitic manipulation: Where are we and where should we go? Behavioural processes, 68(3): 185-199.

Urban, B. C., D. J. Ferguson, A. Pain, N. Willcox, M. Plebanski, J. M. Austyn and D. J. Roberts, 1999. Plasmodium falciparuminfected erythrocytes modulate the maturation of dendritic cells. Nature, 400(6739): 73-77.

Van der Ent, S. and C. M. Pieterse, 2012. Ethylene: Multi-tasker in plant-attacker interactions. Annual Plant Reviews, 44: 343-377.

Vitti, A., E. Pellegrini, C. Nali, S. Lovelli, A. Sofo, M. Valerio, A. Scopa and M. Nuzzaci, 2016. Trichoderma harzianum t-22 induces systemic resistance in tomato infected by cucumber mosaic virus. Frontiers in Plant science, 7.

Vlot, A. C., D. M. A. Dempsey and D. F. Klessig, 2009. Salicylic acid, a multifaceted hormone to combat disease. Annual review of phytopathology, 47: 177-206.

Werner, B. J., T. M. Mowry, N. A. Bosque-Pérez, H. Ding and S. D. Eigenbrode, 2009. Changes in green peach aphid responses to potato leafroll virus-induced volatiles emitted during disease progression. Environmental entomology, 38(5): 1429-1438.

Yang, Y.-X., G. J Ahammed, C. Wu, S.-y. Fan and Y.-H. Zhou, 2015. Crosstalk among jasmonate, salicylate and ethylene signaling pathways in plant disease and immune responses. Current Protein and Peptide science, 16(5): 450-461.

Yu, D., B. Fan, S. A. MacFarlane and Z. Chen, 2003. Analysis of the involvement of an inducible arabidopsis rnadependent rna polymerase in antiviral defense. Molecular plant-microbe interactions, 16(3): 206-216.

Zhang, H., Y. Hong, L. Huang, S. Liu, L. Tian, Y. Dai, Z. Cao, L. Huang, D. Li and F. Song, 2016. Virus-induced gene silencing-based functional analyses revealed the involvement of several putative trehalose-6-phosphate synthase/phosphatase genes in disease resistance against botrytis cinerea and pseudomonas syringae pv. Tomato dc3000 in tomato. Frontiers in plant science, 7.

Zhu, F., D.-H. Xi, S. Yuan, F. Xu, D.-W. Zhang and H.-H. Lin, 2014. Salicylic acid and jasmonic acid are essential for systemic resistance against tobacco mosaic virus in nicotiana benthamiana. Molecular plant-microbe interactions, 27(6): 567-577. 